\title{
CARACTERÍSTICAS DE LAS SOLUCIONES DE CLORHEXIDINA AL $2 \%$ Y AL 0,2\% EN PREPARACIONES CAVITARIAS EN ODONTOLOGÍA: UNA REVISIÓN
}

\section{CHARACTERISTICS OF 2\% AND 0.2\% CHLORHEXIDINE SOLUTIONS IN CAVITATION PREPARATIONS IN DENTISTRY: A REVIEW}

\author{
TÍTULO CORTO: CARACTERÍSTICAS DE LAS SOLUCIONES DE CLORHEXIDINA AL 2\% Y AL 0,2\%
}

\author{
Jair Utria-Hoyos ${ }^{\circledR}$, Efraín Pérez-Pérez ${ }^{2}$, Martha Rebolledo-Cobos ${ }^{\circledR}$, Alfredo Vargas-Barreto $\left.{ }^{(}\right)$
}

Tipología: Artículo de revisión

Para citar este artículo: Utria-Hoyos J, Pérez-Pérez E, Rebolledo-Cobos M, Vargas-Barreto A. Características de las soluciones de clorhexidina al $2 \%$ y al 0,2\% en preparaciones cavitarias en odontología: una revisión. Duazary. 2018 mayo; 15 (2): 181 - 194. DOI: http://dx.doi.org/10.21676/2389783X.2103

Recibido en febrero 08 de 2017

Aceptado en mayo 11 de 2017

Publicado en línea en noviembre 01 de 2017

\section{RESUMEN}

$\mathrm{Al}$ analizar el estudio de la durabilidad en las restauraciones dentales, la clorhexidina aparece como un agente antibacteriano de amplio espectro, con capacidad de inhibir la actividad proteolítica de algunas enzimas que pueden degradar las fibras colágenas de la capa híbrida y de aumentar la capacidad de adhesión en una restauración. Este artículo analiza los aspectos generales en las soluciones de clorhexidina a dos concentraciones diferentes, observando los beneficios o desventajas que presentan sobre el barrillo dentinario y la posibilidad de que una restauración tenga mejor fijación sobre la dentina. Para la obtención del material, se realizó una búsqueda basada en la literatura, utilizando como fuente las bases de datos PubMed y Scielo. Se emplearon los descriptores de búsqueda: "clorhexidine", "dentine", "solutions", y se relacionaron con los términos: "cavity preparations", "desadaptaciones", "recurrence decay". Los resultados de la presente revisión evidencian que las sustancias de clorhexidina en el campo odontológico son de gran utilidad e importancia porque proporcionan múltiples resultados cuando son aplicadas en procesos de restauración y tejidos adyacentes a la misma. Al aplicar el $2 \%$ de clorhexidina, esta presenta mejor eficacia que si se aplicara solo el $0,2 \%$.

Palabras clave: dentina; clorhexidina; soluciones; barrillo dentinario; adhesión.

1. Odontólogo, Universidad Metropolitana de Barranquilla. Colombia. Correo: jutria@unimetro.edu.co - http://orcid.org/0000-0002-0547-2467

2. Odontólogo, Universidad Metropolitana de Barranquilla. Colombia, Correo: efjunior84@hotmail.com - http://orcid.org/0000-0002-0143-2994

3. Odontóloga, Estomatóloga y Cirujana Oral, Magíster en Genética Molecular, Universidad Metropolitana de Barranquilla. Colombia. Correo: mrebolledo@unimetro.edu.co - http://orcid.org/0000-0002-0488-2464

4. Rehabilitador Oral. Universidad Metropolitana de Barranquilla. Colombia. alvaba@hotmail.com - http://orcid.org/0000-0003-3861-1168 


\section{CARACTERÍSTICAS DE LAS SOLUCIONES DE CLORHEXIDINA AL 2\% Y AL 0,2\% EN PREPARACIONES \\ CAVITARIAS EN ODONTOLOGÍA: UNA REVISIÓN}

\section{ABSTRACT}

In analyzing the study of durability in dental restorations, chlorhexidine appears as a broad spectrum antibacterial agent capable of inhibiting the proteolytic activity of some enzymes that can degrade the collagen fibers of the hybrid layer and increase the adhesion capacity In a restoration. This article analyzes the general aspects of chlorhexidine solutions at two different concentrations, observing the benefits or disadvantages they present on the dentin barrel and the possibility that a restoration has better fixation on the dentin. To obtain the material, a search was made based on the literature, using as source the PubMed and Scielo databases. The search descriptors were used: "chlorhexidine", "dentine", "solutions", and related to the terms "cavity preparations", "recurrence decay". The results of the present review show that chlorhexidine substances in the dental field are of great utility and importance because they provide multiple results when applied in restoration processes and tissues adjacent to it. When applying $2 \%$ chlorhexidine, it presents Better than $0.2 \%$.

Keywords: Dentin; Chlorhexidine; Solutions; Smear Layer; Adhesion.

\section{INTRODUCCIÓN}

$\mathrm{P}$ omacondor ${ }^{1}$ demostró que en la segunda mitad del siglo XX aumentó el índice de importancia biológica para preservar las estructuras dentarias en todo procedimiento restaurador; como respuesta a esta necesidad surgió el desarrollo de los sistemas adhesivos. Con lo anterior, se facilitó satisfacer otras características como lo es la estética de las restauraciones dentales -que ayudan a una mayor permanencia de una restauración en la cavidad oral-y la compatibilidad que pueda existir entre el material restaurador y el diente.

Autores como Charone et $a l^{2}$ señalan que los túbulos dentinarios ocupan el espesor de la dentina, desde la cámara pulpar hasta el límite amelodentinario, alojando dentro de cada túbulo las prolongaciones citoplasmáticas de los odontoblastos. Debido a la presencia de estos túbulos, la pulpa y la dentina se mantienen interconectadas estructural y funcionalmente, actuando de manera conjunta en los distintos procesos de salud-enfermedad a los que se ven enfrentadas. Silva et $a l^{3}$ indican que, al realizar preparaciones cavitarias sobre la dentina, se produce una sustancia llamada barrillo dentinario; la capa de detritus dentinaria puede funcionar como área de depósito de microorganismos que facilite el acceso directo a la pulpa, causando injuria, o puede ser una barrera de protección con un efecto benéfico, al actuar como fondo cavitario que puede reducir con cierta efectividad la permeabilidad de la dentina y protegerla de estímulos externos. Por ende, conociendo la composición química en estudios realizados y sus defectos en esta, se pretende utilizar los colutorios de clorhexidina y los geles, los cuales reducen significativamente los conteos de Streptococcus mutans en individuos que son propensos a la caries ${ }^{4}$.

Así mismo, Cherian et al , logran evidenciar que durante el proceso de adhesión se produce la formación de la capa híbrida, constituida por colágeno desmineralizado, infiltrado por el adhesivo de la resina compuesta. Se ha atribuido la responsabilidad de la pérdida de fuerza y durabilidad de los adhesivos a la degradación de esta capa por acción de las metaloproteinasas de la dentina. Un inhibidor es la clorhexidina; se ha observado que esta retarda la degradación de la capa híbrida, mejorando el proceso de adhesión. En la misma línea, se han demostrado valores de resistencia a la tracción de restauraciones de 
resina compuesta, realizadas en dientes tratados con desinfección con clorhexidina (CHX), los cuales son significativamente mayores que en dientes no tratados 5 .

La sustancia de CHX es implementada en los tratamientos de operatoria dental buscando un campo de actividad antibacteriana y favorecen cualquier tratamiento que sea implementado en el campo odontológico, el cual permite la degradación de la capa híbrida, producto de los diferentes tipos de metaloproteinasas (MMPs) ${ }^{6}$. En este contexto, Trufello ${ }^{7}$ expresa que la acción de CHX en MMPs es de utilidad frecuente, teniendo en cuenta que las células de fibrosarcoma humano y las células de mamíferos determinaron que tenía una acción inhibidora.

Por otro lado, Hebling ${ }^{8}$ logró establecer que la actividad colagenolítica endógena determina que existe actividad de dentina mineralizada producida por dientes extraídos, en representación de la desintegración de fibras colágenas. Asimismo, Hebling afirma que el uso de CHX disminuye en una proporción la degradación de la fase adhesiva durante un período de tiempo. Por su lado, Mistry et $a l^{9}$ manifiestan que esta solución tiene actividad antimicrobiana, antifúngica, antibacteriana de amplio espectro contra microorganismos, tanto Gran positivo como Gran negativo, hongos, dermatofitos y algunos virus.

Según los anteriores planteamientos, este estudio busca realizar un análisis donde se relacionen los aspectos generales en las soluciones de CHX y su aplicabilidad en la odontología, especificando los beneficios o desventajas que presentan sobre el barrillo dentinario y la posibilidad de que una restauración tenga óptima fijación sobre la dentina, durante procedimientos en odontología restauradora.

\section{MATERIALES Y MÉTODOS}

\section{Estrategia de búsqueda}

Para hallar la literatura que fundamenta este estudio, se realizó una búsqueda sistemática en los idiomas español e inglés, en las bases de datos globales: PubMed, Scielo y Ovid. Allí se emplearon los descriptores de búsqueda: "clorhexidine", "dentine", "solutions", y se relacionaron con los términos: "cavity preparations", "desadaptaciones", "recurrence decay", "alteraciones en barrillo dentinario". La búsqueda también incluyó aspectos como los mecanismos de acción de la clorhexidina, la sustantividad, el espectro de acción, la capa híbrida, la permeabilidad dentinaria y la adhesión. Se incluyeron cincuenta artículos científicos publicados en revistas internacionales en los últimos diez años.

\section{Criterios de búsqueda}

Para ser incluídos en esta revisión, los documentos debían proporcionar información sobre las características que presenta la clorhexidina a diferentes concentraciones; mostrar el efecto que proporciona la clorhexidina en operatoria dental al 2\% y 0,2\%; y especificar el uso de las diferentes concentraciones de clorhexidina (en inglés). Se excluyeron los estudios que tenían más de diez años de haber sido publicados y aquellos que no estaban publicados en revistas internacionales.

\section{RESULTADOS}

\section{Clorhexidina}

Existen diversas definiciones y usos de la CHX. En la odontología restauradora, la CHX fue usada inicialmente como antiséptico al momento de realizar preparaciones cavitarias; se 


\section{CARACTERÍSTICAS DE LAS SOLUCIONES DE CLORHEXIDINA AL 2\% Y AL 0,2\% EN PREPARACIONES CAVITARIAS EN ODONTOLOGÍA: UNA REVISIÓN}

utilizaba antes de la aplicación de los materiales restauradores para eliminar las bacterias que podían irritar la pulpa dental, lo que tuvo como consecuencia la sensibilidad posoperatoria y la caries secundaria ${ }^{10,11}$.

Mesias $^{12}$, en el año 1954, reportó antecedentes históricos de la CHX; describió al gluconato en fórmula simple para luego sintetizarlo en 1957 y proporcionar una poliguanida antimicrobiana de amplio espectro para ser usada en humanos, como fue en el caso de Gran Bretaña donde se usó como crema antiséptica para heridas en la piel. El gluconato de $\mathrm{CHX}$, al igual que el clorhidrato de CHX y el acetato de CHX, son solubles en agua y en alcohol, lo que aumenta su efectividad antimicrobiana en la cavidad oral y sus tejidos adyacentes ${ }^{12}$.

Yadiki et al ${ }^{13}$ señalaron, al respecto, que el gluconato de CHX es un agente antimicrobiano utilizado ampliamente como inhibidor y letal para vegetativas Gran positivo y Gran negativo, relativamente en altas diluciones. La sustantividad y el amplio espectro de la actividad bacteriana son características principales de la CHX que contribuyen a su éxito como un agente antiplaca. Se crea un ambiente bacteriostático mediante la unión a las superficies orales y la posterior liberación del compuesto durante un largo período de tiempo. Por lo tanto, se han propuesto diferentes enfoques para mejorar la resistencia de la unión y la infiltración de monómero en la dentina desmineralizada, los cuales han contribuido a la reducción para la tasa de absorción en agua y a la degradación en colágeno expuesto y matriz de resina. Entre los enfoques más mencionados en la literatura, se ha propuesto el uso de inhibidores de MMP, como el digluconato de $\mathrm{CHX}^{14}$.

Otras propiedades constitutivas de la $\mathrm{CHX}$ fueron descritas por Mohammed ${ }^{15}$, quien deter- minó que la CHX actúa como un inhibidor de la MMP para la desinfección antes de colocar una restauración, evitando así la pérdida de la integridad de la capa híbrida. La CHX también minimiza los flujos de agua por evaporación de la dentina, generando así un mejor resultado: la unión resina-dentina. Abouassi et al ${ }^{16}$ analizaron que el compuesto de $\mathrm{CHX}$ se ve afectado por las sustancias orgánicas; hay que tener en cuenta que su aplicación al 0,2\% presenta excelentes resultados al reducir la formación de placa y compuestos antibacterianos en la cavidad oral. Cabe resaltar que las diferentes formas de CHX se utilizan comúnmente en odontología, y todas han aportado múltiples beneficios.

La CHX, entonces, se determina como una molécula que se une a diversas proteínas por un mecanismo catiónico de quelación. Esta tiene la capacidad de inhibir la actividad catalítica de MMP mediante la unión con zinc o calcio para aumentar en mayor proporción la resistencia ${ }^{14,16}$. Es necesario señalar que el uso de CHX como agente de pretratamiento de fibras de colágeno en dentina desmineralizada por ácido ortfosfórico, no tiene ningún efecto adverso sobre la resistencia ${ }^{17}$.

Al respecto, cabe mencionar el estudio de Flury et $a l^{14}$, quienes aplicaron la CHX posterior al acondicionamiento ácido para obtener como resultado la estabilización en relación entre el material restaurador y la dentina. Así, lograron la desinfección de la cavidad y la degradación de las fibras de colágeno que fueron desmineralizadas y no infiltradas por los compuestos resinosos, y, de esta manera, se evitó la degradación de adherencia con el tiempo.

En esta línea, el estudio de Mazzoni ${ }^{18}$ determinó que la membrana celular se ve afectada por la actividad metabólica que presenta la CHX entrando en contacto directo con la 
saliva, la cual contiene diferentes proteínas que serían compatibles con la solución, lo que lleva a la eliminación o destrucción de la misma. Por otra parte, los hallazgos de Saffarpour ${ }^{19}$ demostraron que además de la aplicación de la solución de CHX, una restauración se ve obligada a ser implementada como un método más práctico que otras técnicas para la rehidratación de la dentina desmineralizada, secado a presión con la jeringa triple y preservación de la humedad necesaria para evitar la degradación de las fibras de colágeno. Prasad ${ }^{20}$ consideró que las moléculas de CHX que ingresan a las células son consideradas como el mejor agente de control para la placa y la coagulación de las proteínas que causan disminución de la actividad de células vitales y que resultan en la muerte celular.
Priyadarshini et $a l^{21}$ identificaron los beneficios desinfectantes y antimicrobianos de la CHX y la examinaron, en diferentes concentraciones -las cuales presentan diferentes ventajas y desventajas (Tabla 1), como una opción terapéutica en la preservación de las capas híbridas en dentina humana, aplicando adhesivos de grabado y enjuague; se aplica CHX sobre las fibrillas de colágeno expuestas y luego es sellada en su lugar con materiales compuestos de resina adhesiva que tiene la capacidad de proteger el colágeno contra un ataque colagenolítico, lo que retrasa la degradación típica al momento de implementar adhesivos dentales. Sin embargo, esto no depende de la dosis porque en altas concentraciones tiene la capacidad de desactivar la MMPs por desnaturalización de la enzima, en lugar de la quelación de los cationes.

Tabla 1. Comparación del efecto de clorhexidina en barrillo dentinario.

\begin{tabular}{|c|c|c|}
\hline & Clorhexidina al $2 \%$ & Clorhexidina al 0,2 \% \\
\hline \multirow{4}{*}{ Diferencias } & $\begin{array}{l}\text { Singh et } a l^{46} \text { señalaron que la retención de las } \\
\text { restauraciones es mucho mayor utilizando la } \\
\text { clorhexidina al } 2 \% \text {. }\end{array}$ & $\begin{array}{l}\text { Singh et } a l^{46} \text { observaron que la retención } \\
\text { de las restauraciones es menor utilizando } \\
\text { clorhexidina } 0,2 \% \text {. }\end{array}$ \\
\hline & $\begin{array}{l}\text { Breschi et } a^{22} \text { indicaron que el } 2 \% \text { de CHX } \\
\text { impide la mayor parte de la disminución de } \\
\text { la resistencia de la MMPs en la unión del } \\
\text { proceso adhesivo en dentina, tanto en dientes } \\
\text { temporales como permanentes. }\end{array}$ & $\begin{array}{l}\text { Breschi et } a^{22} \text { observaron que la CHX } \\
\text { contiene un papel protector de } 0,2 \% \text {. A menor } \\
\text { concentración de CHX es igual de eficaz en } \\
\text { comparación con el } 2 \% \text {. }\end{array}$ \\
\hline & $\begin{array}{l}\text { Bohari et al }{ }^{47} \text { indicaron que la aplicación de } \\
\mathrm{CHX} \text { al } 2 \% \text { tiene efectos beneficiosos, pues } \\
\text { evita la degradación de las fibras de colágeno } \\
\text { si es aplicada después del acondicionamiento } \\
\text { ácido y la aplicación de adhesivo. }\end{array}$ & $\begin{array}{l}\text { Abu } e a^{30} \text { señalaron que la clorhexidina al } 0,2 \% \\
\text { es suficiente para preservar la resistencia en la } \\
\text { adhesión en el proceso de una restauración. }\end{array}$ \\
\hline & $\begin{array}{l}\text { Echeverri }^{48} \text { observó la inhibición de } \\
\text { crecimiento de E. faecalis en la dentina. }\end{array}$ & $\begin{array}{l}\text { Breschi et } a^{22} \text { mencionaron que la } \mathrm{CHX} \\
\text { previa a una restauración es un inhibidor de } \\
\text { la MMP- } 2 \text {. }\end{array}$ \\
\hline
\end{tabular}




\begin{tabular}{|c|c|c|}
\hline & Clorhexidina al $2 \%$ & Clorhexidina al 0,2 \% \\
\hline \multirow{2}{*}{ Diferencias } & $\begin{array}{l}\text { Carrilho et } a l^{49} \text { notaron que existe menor } \\
\text { resistencia en los procesos de adhesión al } 2 \% \\
\text { de CHX en comparación con el } 0,2 \% \text { de CHX. }\end{array}$ & $\begin{array}{l}\text { Carrilho et } a l^{4} \text { hallaron que existe mayor } \\
\text { resistencia en los procesos de adhesión } 0,2 \% \\
\text { de CHX en comparación con } 2 \% \text { de CHX. }\end{array}$ \\
\hline & $\begin{array}{l}\text { Shafiei et } a^{50} \text { observaron que existe la } \\
\text { probabilidad de inactivar la MMPs por } \\
\text { desnaturalización de la enzima. }\end{array}$ & $\begin{array}{l}\text { Shafiei et } a l^{50} \text { buscaron determinar que el } \\
\text { efecto de inhibición de la clorhexidina en } \\
\text { MMPs es por la quelación de los cationes de } \\
\text { la enzima. }\end{array}$ \\
\hline Semejanzas & \multicolumn{2}{|c|}{$\begin{array}{l}\text { - Inhiben tanto en altas como en bajas concentraciones directamente la actividad de MMP- } \\
-8 \text { y }-9^{50} \text {. } \\
\text { - Impiden la mayor parte de la disminución de la resistencia de la unión resina-dentina en } \\
\text { dientes temporales y permanentes }{ }^{11,50} \text {. }\end{array}$} \\
\hline
\end{tabular}

Otros autores como Breschi et al ${ }^{22}$ observaron el papel activo de la dentina MMP-2 en la degradación de la capa híbrida y proponen el uso de CHX como cebador adicional para su efecto inhibidor sobre la dentina con la actividad de MMP-2. El 2\% de CHX impidió la mayor parte de la disminución de la resistencia de la unión en dientes temporales y permanentes. Además los autores sugieren el rol de la CHX 0,2\% como protector, pasado un año de almacenamiento de las muestras unidas en saliva artificial, lo que sugiere que la menor concentración de $\mathrm{CHX}$ sea igual de eficaz en comparación con el $2 \%{ }^{23}$.

Investigaciones realizadas por Felembar et $a^{24}$ confirman las propiedades favorables de la CHX, sin embargo, se ha expuesto que además de tener sus efectos antimicrobianos, impide la degradación de las fibras de colágeno por causa de la MMP, favoreciendo la adhesión a la dentina a mediano y largo plazo cuando es aplicada posterior al acondicionamiento ácido. Al respecto, Hussein et $a l^{25}$ lograron determinar que existen diferentes enfoques para mejorar la resistencia de la unión en los grupos donde es utilizado el compuesto de CHX, en la infiltración de monó- meros de dentina desmineralizada, buscando la reducción para la degradación de colágeno expuesto y la absorción de agua.

A la aplicación de la solución de CHX a concentración del $2 \%$ por 60 segundos, luego del grabado ácido y luego de ser aplicada, se le añade el sistema adhesivo simplificado para obtener gran variedad de efectos benéficos, como la desinfección de la cavidad y la degradación de las fibras colágenas que fueron desmineralizadas y no infiltradas por los monómeros resinosos ${ }^{26}$. Carrilho et $a l^{2}$ observaron que el $2 \%$ de clorhexidina aplicado en seguida del grabado ácido preserva tanto la durabilidad de la capa híbrida como la resistencia de la restauración. En la misma línea, Sánchez et $a^{28}$ determinaron el efecto beneficioso que posee la clorhexidina al $2 \%$ al proporcionar estabilidad a la capa híbrida; al aplicar esta sustancia se mostró una fuerza de adhesión que favorece la restauración, comparada con la técnica convencional de adhesión sin desinfección (Tabla 1).

Aquí cabe mencionar el trabajo de Sánchez et $a l^{28}$; en el que explican cómo, a bloques de resina 
sobre cavidades tratadas y almacenadas en aguda a $37^{\circ} \mathrm{C}$ por 24 horas, se les realizaron cortes transversales que fueron sometidos a ciertas fuerzas tensionales. A partir de este experimento pudieron argumentar que la clorhexidina al $2 \%$ no genera diferencias en la fuerza de adhesión, antes o después del acondicionamiento ácido, con respecto en un control y el grupo estudiado. Se indica que ni la aplicación de solución de Clorhexidina 2\%, ni el tiempo de acción de la misma influyen en la conductancia hidráulica (el flujo del fluido a través de la dentina, a través de la presión hidrostática) de discos de dentina humana ${ }^{29}$.

Otros investigadores como $\mathrm{Abu}$ et $\mathrm{al}^{30}$ informaron que, durante un máximo de seis meses bajo todas las condiciones de clorhexidina probadas, con independencia de su concentración y tiempo de aplicación, el uso de clorhexidina al 0,2\% parecía ser suficiente para preservar la resistencia al cizallamiento total del adhesivo de grabado a la dentina. En un estudio in vitro observaron que la fuerza de adhesión es igual en una dentina pretratada, con o sin soluciones de clorhexidina al 0,2\%, luego de ser acondicionadas con ácido ortofosfórico ${ }^{28,30}$.

Bidar $^{31}$ identificó que la CHX es un agente antimicrobiano eficaz que actúa contra bacterias Gram positivas y Gram negativas, virus, mohos y anaerobios facultativos y aerobios. $\mathrm{Su}$ mecanismo de acción se explica por el daño a la pared celular y por las fugas de los componentes intracelulares y eventual muerte de los microorganismos. Al respecto, $\mathrm{Mali}^{32}$ señaló que el inicio o la progresión de la enfermedad periodontal tiene la posibilidad de ser controlado por medidas regulares y un minucioso control de la placa. El control mecánico de la placa es la práctica de higiene oral más confiable para mantener una correcta higiene bucal. Se debe tener en cuenta que el uso de CHX en el protocolo de enlace, luego de la desmineralización con ácido fosfórico, con el fin de estabilizar la interfaz de unión y evitar la degradación de resistencia a la adherencia con el tiempo, ya ha sido probado.

Así como este, otros estudios han demostrado sus ventajas sobre otros agentes inhibidores de la placa potencialmente útiles. Posteriormente de estos estudios, otros afirman que al 0,1-0,2\% en enjuague bucal, es la solución que día a día se ha convertido en un tratamiento prescrito por los odontologos ${ }^{33}$.

\section{Mecanismo de acción de la clorhexidina}

Son varios los autores que argumentan los mecanismos de acción de la CHX. Mesías ${ }^{12}$, determinó que la $\mathrm{CHX}$, en bajas concentraciones, tiene efectos bacteriostáticos, se une a la membrana celular de las bacterias y produce un aumento de la permeabilidad. Este mecanismo de acción se da a lugar por la interacción reversible de la molécula de $\mathrm{CHX}$ con grupos fosfato, sulfato y carboxilo de los tejidos blandos y duros. Esta se libera gradualmente de ocho a doce horas en su forma activa y después de 24 horas aún al encontrarse en concentraciones bajas, lo que evita la colonización bacteriana durante ese tiempo gracias a que está en una liberación constante, en la bolsa periodontal y tejidos adyacentes, para así ser absorbida rápidamente. Esta se activa frente a bacterias Gram positivo y Gram negativo, que manejen un $\mathrm{PH}$ entre 5,0 y 8,0 ya que su $\mathrm{PH}$ óptimo se encuentra entre esos rangos.

La eficacia de CHX como un agente antimicrobiano, o como un agente antiproteolítico, se ha relacionado con su sustantividad a las estructuras orales, en una alianza prolongada entre un material (como la CHX) y un sustrato (como la mucosa oral, las proteínas orales, la placa dental y la superficie dental), una asociación que posibilidad de ser mayor y más prolongado de 


\section{CARACTERÍSTICAS DE LAS SOLUCIONES DE CLORHEXIDINA AL 2\% Y AL 0,2\% EN PREPARACIONES \\ CAVITARIAS EN ODONTOLOGÍA: UNA REVISIÓN}

lo esperado a partir de un simple mecanismo de deposición ${ }^{34}$. La matriz de dentina humana contiene al menos MMP tipo dos y MMP tipo nueve, por lo tanto, si se presenta una completa infiltración de las fibras colágenas, el adhesivo conduce la exposición de las fibras.

Cabe mencionar que la MMPs son un grupo de 23 enzimas capaces de degradar todos los componentes de la matriz extracelular ${ }^{35}$. Por lo tanto, se considera que la administración de un agente a su sitio de acción, en una forma biológicamente activa, y en dosis eficaces, aumenta este efecto de agente durante períodos prolongados de tiempo ${ }^{35}$. Otras investigaciones realizadas por Fan $^{36}$ concluyen que la CHX no puede sugerirse para ser usada como agente para desinfección de cavidad oral, sino para ser implementada en protocolos de rehabilitación dental por mostrar una excelente sustantividad en la superficie de la dentina para alargar los efectos antibacterianos.

\section{Sustantividad de la clorhexidina}

La sustantividad de la CHX, o su capacidad para ser retenida en matrices de dentina, podría ser la razón por la que la dentina grabada con ácido CHX, tratada para formar capas híbridas, sea más estable en el tiempo. El éxito de CHX en el aumento de la durabilidad de las uniones resinadentina requiere que se hagan más esfuerzos en cuanto a la comprensión de los mecanismos responsables de la $\mathrm{CHX}$, la unión a la dentina mineralizada y desmineralizada, para optimizar la manera en la que debe utilizarse clínicamente la CHX para maximizar su retención y eficacia. Los estudios sobre la sustantividad de la $\mathrm{CHX}$ a las estructuras orales comenzaron en los años setenta. La mayoría de estos estudios investigaron la retención de la CHX en las superficies orales con el fin de determinar su capacidad para inhibir o reducir el crecimiento bacteriano/actividad. En consecuencia, siempre y cuando se controlaron el número y el crecimiento de bacterias, la CHX sería considerada eficaz. Sin embargo, la inhibición prolongada de las bacterias de crecimiento en la actividad es meramente una manera indirecta para estimar la sustantividad de CHX a estructuras orales, y puede no ser apropiada para explicar su función antiproteolítica a largo plazo ${ }^{37}$.

\section{Espectro de acción de la clorhexidina}

La CHX posee un muy amplio espectro frente a microorganismos Gram negativo y Gram positivo. La clorhexidina tiene actividad para reducir la producción de ácido a partir de glucosa por estreptococos orales, también destruye la placa formada al competir con el ion calcio, factor que ayuda, de cierto modo, a la formación y crecimiento de la placa bacteriana, la cual actúa como una molécula que permite a las bacterias fijarse a la película adquirida sin impedimentos ${ }^{12}$.

La CHX tiene un uso importante en odontología y estomatología; esta se encuentra indicada en la inhibición farmacológica de la formación de la placa dental y periodontal supragingival, $y$ suele ser recomendada antes y después de los tratamientos periodontales por su eficacidad en la placa subgingival gracias a su adsorción a la superficie dental y a la mucosa oral que hace que sus efectos persistan hasta 48 horas luego de la aplicación del producto $^{38}$. Según Ganesh ${ }^{39}$, la CHX posee la propiedad de la sustantividad, la cual se determinó que inhibía la formación de la biopelícula, obteniendo la adhesión prolongada de CHX a los túbulos dentinarios y paredes del canal radicular, lo que explica el éxito en los tratamientos dentales.

También se ha recomendado su uso como antiséptico bucal en el tratamiento de infecciones de la orofaringe (en gargarismos) y en la desinfección de prótesis, férulas o placas de descarga y 
aparatología ortodóntica. Los barnices parecen desarrollar un buen efecto protector frente a la flora cariogénica, en diversos tipos de pacientes ${ }^{40}$.

La clorhexidina tiene un amplio espectro de acción antibacteriana y antifúngica aplicadas en dentina, con capacidad de inhibir la actividad catalítica de MMP mediante la unión con zinc o calcio, obteniendo paredes reforzadas por los niveles de $\mathrm{pH}$ entre 5,5 y 7,0 las cuales permanecen en un $\mathrm{PH}$ neutro ${ }^{41}$.

Los resultados reportados en la literatura y demostrados en la bibliografía consultada indican que la $\mathrm{CHX}$, con el tiempo, evita la degradación de la capa híbrida y la interfaz de enlace. Además de presentar un espectro antimicrobiano amplio bien conocido, las soluciones de CHX también tienen sustantividad ${ }^{14,41}$. El trabajo de Hameed ${ }^{42}$ demuestra que la existencia de $S$ mutans en cavidad oral es frecuente y que suele encontrarse en las fisuras oclusales y en las superficies radiculares expuestas; por lo tanto, al momento de hacer restauraciones de cavidades oclusales se sugiere que el uso de solución de CHX al 2\% para el tratamiento de la preparación de la cavidad, antes de colocar la restauración, podría ayudar a reducir la caries residual y la sensibilidad postoperatoria.

La sustantividad hace referencia a la capacidad de la CHX, después de la aplicación del material, de mantenerse activa en la superficie de los dientes durante períodos prolongados, lo cual tiene algunas ventajas en la acción de CHX en el largo plazo. Sin embargo, el uso de CHX tratamiento previo ha mostrado resultados controvertidos y no siempre es capaz de preservar la estabilidad interfaz adhesiva a largo plazo ${ }^{14,42}$. Autores como Da silva et $a l^{43}$, observaron que el mecanismo por el cual se produce la degradación de la interfaz de enlace todavía no está completamente claro. No obstante, este proceso es definido como un fenómeno complejo que implica sustratos (dentina y sistemas adhesivos) y se ve afectado negativamente por la acción del agua (degradación hidrolítica) y enzimas presentes en la dentina (degradación enzimática).

\section{Capa híbrida}

La capa híbrida es el resultado de la íntima relación que se forma entre los monómeros resinosos y los sustratos de dentina pretratada. La dentina desmineralizada y la fibras de colágeno forman dicha capa, la cual podrían evitar la presencia de hipersensibilidad y caries recurrente en la odontología restauradora si se logra sellar el intervalo que hay entre la dentina y el material restaurador ${ }^{28,43}$.

\section{Mecanismos de la formación de la capa híbrida}

La capa de detritus dentinaria es el resultado de la remoción de la capa superficial de dentina en cierta profundidad, producto de la aplicación de ácidos o agentes quelantes del calcio ${ }^{28,43}$.

La efectiva aplicación del agente adhesivo puede alterar o modificar la elasticidad, humectabilidad y el posicionamiento de las fibras de colágeno para, así, favorecer una mejor penetración de los componentes restauradores ${ }^{28,43}$.

\section{Permeabilidad dentinaria}

Sanabe et al ${ }^{29}$ definieron la permeabilidad dentinaria como el paso de fluidos, iones, moléculas, partículas y bacterias a través de la dentina, bajo diferentes condiciones. En 1914, se realizó la primera penetración de sustancias a través de la dentina. Algunas décadas más tarde, en 1946, se realizó un reconocido experimento: aplicaron una sustancia colorante en una cavidad profunda y luego de un tiempo determinado observaron cómo el colorante se difundió a la dentina, a la 
pulpa y al esmalte próximos a la cavidad donde había sido aplicado. De esta forma nació el concepto de permeabilidad dentinaria y desde ese entonces ha sido intensamente investigado en odontología con distintos fines, entre ellos, el estudio del efecto del barro dentinario, los tratamientos químicos y el flujo de fluidos en cavidades $^{29,44}$.

\section{Factores que determinan la permeabilidad dentinaria}

Una deficiencia muy común en los estudios previos de movimiento de fluidos en dentina es que el flujo era medido bajo condiciones pobremente definidas y muchas variables no eran controladas: El grosor de la dentina no era uniforme, el área de dentina expuesta no era descrita, entre otras. Con el fin de solucionar este problema, la conductancia hidráulica de la dentina debe ser cuantificada para proporcionar una descripción de la habilidad del fluido de pasar a través de la dentina. Cabe mencionar que la permeabilidad dentinaria depende de distintas variables que determinan su magnitud; entre las principales: grosor, área de dentina expuesta, barro dentinario, grabado ácido y temperatura ${ }^{44}$.

\section{Adhesión}

La adhesión es un proceso de interacción de sodio o líquidos entre un material y otro, a nivel de una misma interface. Para la mayoría de las soluciones de adhesión dental, consiste en articulaciones adhesivas que es el resultado de interrelaciones de una capa de material intermedio con dos superficies, las cuales dan lugar a dos interfaces adhesivas para obtener distintos mecanismos de adhesión como: química, fuerzas físicas y unión mecánica. Por ello, las técnicas adhesivas que se usan hoy en día consisten, casi siempre, en el empleo de una sustancia líquida que se pone en contacto con un sólido y que luego se hace endurecer por algún mecanismo, físico o químico, para favorecer el contacto de la estructura dentaria y la sustancia líquida ${ }^{44}$.

En esta línea, Mozayeni ${ }^{45}$ demuestra que la eficacia de este material depende de la penetración que exista en los túbulos dentinales donde las bacterias se acumulan. Al existir un taponamiento del mismo se presentan posteriormente fallos en las restauraciones dentales, por lo que debe existir una longevidad de las restauraciones.

El desarrollo ha traído grandes cambios en la odontología restauradora, ya que el éxito clínico de una restauración depende del sellado marginal en la preparación de la cavidad, de los materiales restauradores y del grado de adhesión que estos contengan. Sin embargo, el uso de esta sustancia sigue causando algunos problemas clínicos, particularmente relacionados con la contracción de polimerización y la generación de la tensión en la interface resina-dentina. Estas tensiones obligan severamente a la capa de adhesivo a la formación de vacío, causando microfiltración marginal, caries recurrentes, dolor y sensibilidad postoperatoria ${ }^{14,45}$. Por lo tanto, un procedimiento de unión que proporcione una buena resistencia y longevidad clínica es fundamental para el éxito de las restauraciones estéticas directas con resinas compuestas, por lo que se requiere analizar la efectividad que tiene la clorhexidina al $2 \%$ y $0,2 \%$ en la búsqueda de cada uno de estos objetivos que intervienen en un óptimo proceso de adhesión (Figura 1). 
Figura 1. Se muestra gráficamente el proceso de adhesión y el comportamiento de cada una de las estructuras influyentes en ella, la íntima relación que debe cumplir la dentina recién desmineralizada y los monómeros resinosos. A. Resina, B. Adhesivo, C. Capa híbrida, D. Dentina.

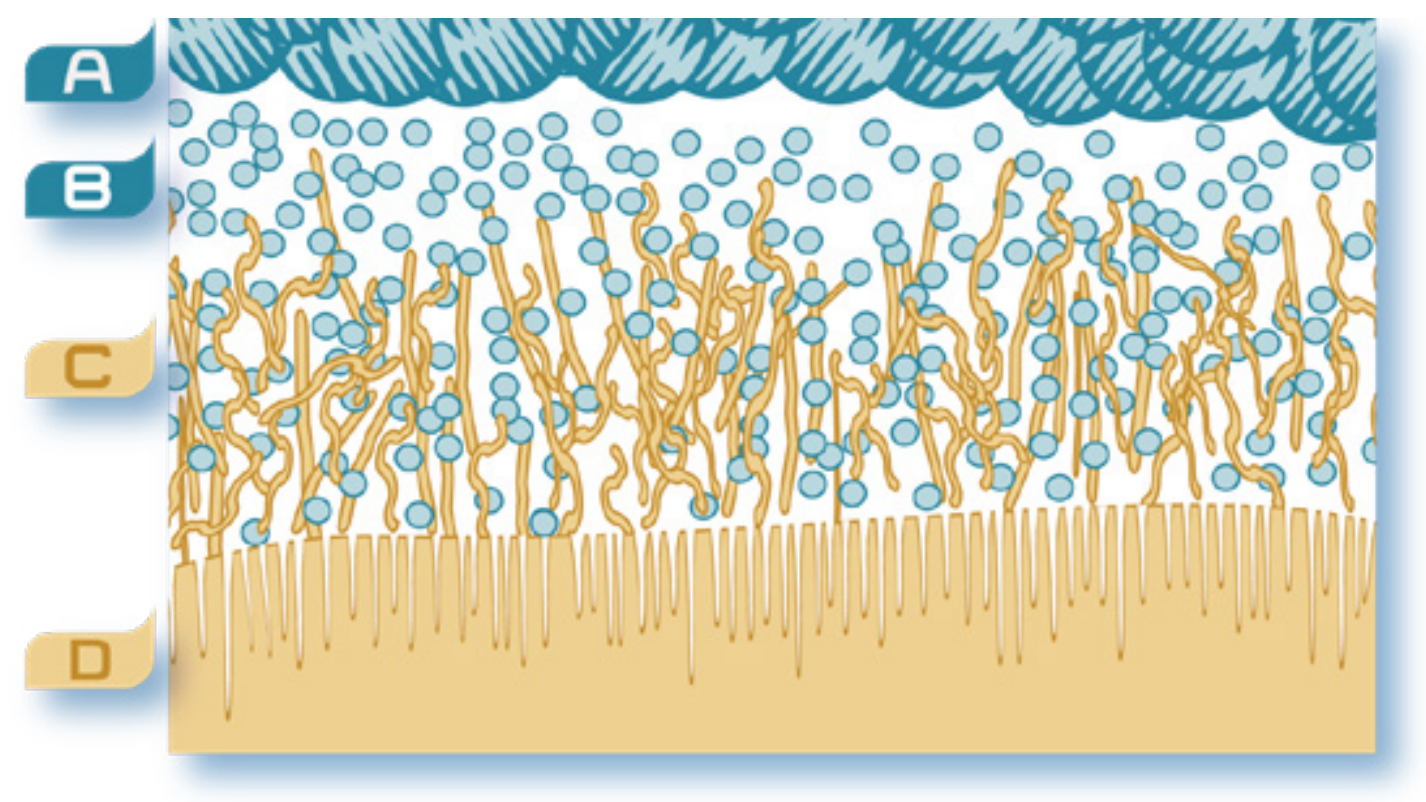

\section{CONCLUSIÓN}

Se logró determinar con este estudio que las sustancias de clorhexidina en el campo odontológico son de gran utilidad e importancia ya que proporcionan múltiples resultados al momento de ser aplicadas en procesos de restauración y tejidos adyacentes. Se logró evidenciar que existe un número mayor de estudios realizados sobre la clorhexidina al $2 \%$ en dentina, a nivel de los procesos de restauración, y un menor número de estudios sobre clorhexidina al 0,2\% en dentina. Asimismo, se logró demostrar que la clorhexidina $2 \%$ proporciona mayor resistencia en los procesos de adhesión. En comparación a la solución de clorhexidina al 0,2 \%, la retención de las restauraciones es mucho mayor, e impide la mayor parte de la disminución de la resistencia de las MMPs en la unión del proceso adhesivo en dentina.

La incorporación de clorhexidina en de los protocolos de aplicación de adhesivos convencionales es un recurso clínico válido para prolongar la degradación de las fibras colágenas de la capa híbrida, pues aumenta la posibilidad de que una restauración tenga mejor fijación sobre la dentina, la cual es la base para medir la unión restauración-dentina. La incorporación de clorhexidina en de los protocolos de aplicación de adhesivos convencionales es un recurso clínico válido para prolongar la degradación de las fibras colágenas de la capa híbrida, pues aumenta la posibilidad de que una restauración tenga mejor fijación sobre la dentina, la cual es la base para medir la unión restauración-dentina. 


\section{DECLARACIÓN SOBRE CONFLICTOS DE INTERESES}

Los autores manifiestan no poseer ningún conflicto de intereses.

\section{REFERENCIAS BIBLIOGRÁFICAS}

1. Pomacóndor-Hernández C. Papel de la clorhexidina en la odontología restauradora. Odontología Sanmarquina. 2010; 13(2): 46-49.

2. Charone S, Cardoso C de A, Kato MT, Ducati P, Fukushima I, Gennaro G. El efecto de los enjuagues bucales que contienen biguanidas en la progresión de la erosión en la dentina. BMC Oral Health. 2014 Oct; 11(10): 14-131.

3. Silva AB, Vidal CM, Leme-Kraus AA, Piresde-Souza FC, Bedran-Russo AK. Cebadores experimentales que contienen compuestos sintéticos y naturales reducen la actividad enzimática en la dentina interfaz-adhesivo bajo cargas cíclicas. Dent Mater. 2016 Oct; 32 (10):1248-1255.

4. Martín J. Aspectos prácticos de la adhesión en dentina. Av. Odontoestomatol. 2004; 20-1: 19-32.

5. Cherian B, Gehlot PM, Manjunath MK. Comparación de la eficacia antimicrobiana de Octenidine Dihydrochloride y clorhexidina con y sin irrigación ultrasónica pasiva - Un estudio in vitro. J Clin Res. 2016 Jun; 10(6):1-7.

6. Lamas C, Angulo G. Restauraciones estéticas en piezas dentarias posteriores aplicando la técnica incremental oblicua $y$ adhesivos de quinta generación. In Crescendo. 2013; 4(2): 349-356.

7. Trufello AM. Las concentraciones subclínicas de clorhexidina inhibieron la actividad de la gelatinasa en la dentina in vitro. J Dent. 2014 Mar; 59(1):81-6.
8. Hebling J, Pashley DH, Tjäderhane L, Tay FR. Chlorhexidine arrests subclinical degradation of dentin hybrid layers in vivo. J Dent Res. 2006 Aug;88(8):741-6.

9. Mistry KS, Sanghvi Z, Parmar G, Shah $S$, Pushpalatha K. Eficacia antibacteriana de Azadirachta indica, elengi Mimusops y el 2\% de CHX en múltiples especies de biopelículas de la dentina. J Conserv Dent. 2015 Nov-Dic; 18(6):461-466.

10. Calsina G, Cerrano J. ¿Existen realmente diferencias clínicas entre las distintas concentraciones de clorhexidina? RCOE. 2005 jul-ago; 10(4): 23-37.

11. Komori PC, Pashley DH, Tjäderhane L, Breschi L, Mazzoni A, de Goes MF, Wang L, Carrilho MR. Efecto de digluconato de clorhexidina al 2\% de la fuerza de adhesión a la normalidad frente a la dentina afectada-caries. Oper Dent. 2009 Mar-Apr; 34(2):157-165.

12. Mesías-Peñaherrera AF. Efecto antimicrobiano de los desinfectantes cavitarios aplicados en las restauraciones dentales. Un Guayaquil. 2014 Jul. 1(1): 9-21.

13. Jampanapalli SR, Konda S, Inguva HC, Chimata VK. Evaluación comparativa de las propiedades antimicrobianas de cementos de ionómero de vidrio con y sin gluconato de clorhexidina. Int J Clin Pediatr Dent. 2016 Apr-Jun; 9(2): 99-103.

14. Flury S, Peutzfeldt A, Schmidlin P, Lussi A. Expuesta la dentina: Influencia de los procedimientos de limpieza y presión simulado pulpar en resistencia de la unión de un sistema adhesivo universal. Plos One. 2017 Jun;12 (1):10-17.

15. Mohammed H. El efecto de diferentes desinfectantes agentes de unión fuerza de resina composites. J Dent. 2014 Mar, 6(2): 231-235. 
16. Abouassi T, Hannig C, Mahncke K, Karygianni L, Wolkewitz M, Hellwig E, et al. Does human saliva decrease the antimicrobial activity of chlorhexidine against oral bacteria? BMC Res Notes. 2014 Oct 10;7:711.

17. Sinha DJ, Jaiswal N, Vasudeva A, Garg P, Tyagi SP, Chandra P. Evaluación comparativa del efecto de la clorhexidina y aloe barbadensis miller (aloe vera) en la estabilización de la dentina utilizando la prueba de adhesión al cizallamiento. J Conserv Dent. 2016 Sep-Oct; 19(5): 406-409.

18. Mazzoni UN. El papel de las MMP en la dentina de la caries, progresión y la estabilidad de bonos. J Dent Res. 2015 Feb; 94 (2): 241-251.

19. Saffarpour UN. Efecto del protocolo de aplicación de clorhexidina en la durabilidad del sellado marginal de las restauraciones de Clase V. J Dent. 2016 Ago; 13 (4): 231-237.

20. Prasad KA. Antiplaca Eficacia de herbario y 0,2\% de gluconato de clorhexidina. Enjuague bucal: un estudio comparativo. J Oral Health. 2015 Ago; 7 (8): 98-102.

21. Priyadarshini BM, Selvan ST, Lu TB, Xie H, Neo J, Fawzy AS. Clorhexidina Nanocápsula. Aproximación de la entrega de fármacos a la interfase dentina-resina. J Dent Res. 2016 Aug; 95(9):1065-1072.

22. Breschi L, Mazzoni A, Nato F, Carrilho M, Visintini E. Clorhexidina estabiliza la interfase adhesiva: 2 años de estudio in vitro. Dent Mater. 2010 Abr; 26(4): 11-15.

23. Parra Lozada M, Garzon Rayo H. Sistemas adhesivos autograbadores, resistencia de unión y nanofiltración: Universidad de Antioquia. Revista Facultad de Odontología. 2012 Feb; 24 (1): 2-7.

24. Felemban NH, Ebrahim M. Efecto de las capas adhesivas sobre la resistencia del enlace de la resina en los compuestos de dentina. J Clin Dent. 2017 Feb; 9 (2): 186-190.
25. Hussein FA, Dos MI, Chalisserry EP, Anil S. El impacto de clorhexidina, enjuague bucal en la fuerza de adhesión de los brackets de policarbonato. J Dent. 2014 Nov; 15 (6):688-692.

26. Parra Lozada M, Garzon Rayo H. Sistemas adhesivos autograbadores, resistencia de unión y nanofiltración. Universidad de Antioquia. Revista Facultad de Odontología. 2012 Feb; 24(1): 32-43.

27. MR, Carvalho, Goes MF. Conserva la dentina de clorhexidina enlace in vitro. J Dent Res. 2007 Ene; 86(1): 90-4.

28. Sánchez Aguilera F, Osorio R, Toledano M. Control del colapso del colágeno: sistemas autograbadores. Av. Odontoestomatol $2004 \mathrm{Jul}$; 20 (4): 175-183.

29. Sanabe ME, Costa CA, Hebling J. Colágeno expuesto en bonos resina-dentina de edad producido en el sonido y caries-afectado dentina en presencia de clorhexidina. Am J Dent. 2009 Feb; 22(1): 37-42.

30. Abu Nawareg M, Elkassas D, Zidan A, Abuelenain D, Abu Haimed T. ¿La clorhexidinametacrilato es tan eficaz como el digluconato de clorhexidina en la preservación de las interfaces de resina dentinaria? J Dent. 2016 Feb; 45(8): 7-13.

31. Bidar M. El efecto de diferentes concentraciones de clorhexidina gluconato en la compresión fuerza de mineraltrioxido agregado. J Dent Res. 2015; 9(1): 1-5.

32. Mali GV. Evaluación comparativa del petróleo con gluconato de clorhexidina al 0,2\% para prevención de placas y gingivitis. J Clin Res. 2016 Jul; 10 (7): 1-4.

33. Pemberton $M$ N, Gibson J. Reacciones de hipersensibilidad a la clorhexidina en odontología. J Dent. 2012 Dic; 213 (11): 547-550. 


\section{CARACTERÍSTICAS DE LAS SOLUCIONES DE CLORHEXIDINA AL 2\% Y AL 0,2\% EN PREPARACIONES CAVITARIAS EN ODONTOLOGÍA: UNA REVISIÓN}

34. Loguercio AD, Hass V, Gutiérrez MF, Luque Martínez-IV, Szezs A. Efectos a cinco años de la clorhexidina in vitro. Durabilidad de las interfases de resina / dentina. J Adhes Dent. 2016; 18(1): 35-42.

35. Dionysopoulos D. Efecto de digluconato de clorhexidina en la fuerza de unión entre los sistemas adhesivos dentales y la dentina: una revisión sistemática. J Conserv Dent. 2016 EneFeb; 19 (1): 11-6.

36. Fan W. Nanopartículas de silicato de calcio mesoporoso cargadas con clorhexidina para las dos propiedades de enterococcus faecalis y mineralización. J Nanobiotecnología. 2016 Oct; 14 (1): 72.

37. Sharafeddin F, Farhadpour H. Evaluación de la resistencia al corte de enlaces y sistemas de autoadhesión total después de la aplicación de clorhexidina a la dentina contaminada con agente hemostático. J Dent. 2015 Sep; 16 (3): 175-181.

38. Chimenos Küstner E. Antisépticos en medicina bucal: la clorhexidina. Universidad de Barcelona. Facultad de Odontología. 2003 Ene; 1 (1): 10-16.

39. Ganesh UN. El efecto de la adición de una enzima degradante de EPS con y sin detergente al $2 \%$ de clorhexidina en la interrupción de Enterococcus faecalis Biofilm: Un escaneo láser confocal, estudio microscópico. J Clin Res. 2015 Nov; 9 (11): 61-5.

40. Gunaydin Z, Yazici AR, Cehreli ZC. Efectos in vivo e in vitro del pretratamiento con clorhexidina sobre la resistencia inmediata y envejecida de la dentina. Oper Dent. 2016 May-Jun; 41(3): 258-67.

41. Jiménez García AF. Estudio comparativo in vitro del efecto antibacteriano del extracto de Allium sativum (ajo) blanco, púrpura y clorhexidina al $0,12 \%$ sobre cepas de Streptococcus mutans [trabajo de investigación para la obtención del título de odontólogo]. Quito: Universidad Central del Ecuador. Facultad de Odontología; 2015.
42. Hameed H. La microfiltración en la restauración de resina compuesta de antimicrobianos pretratamientos con $2 \%$ de clorhexidina con la protección de los enlaces. Int J Oral Health. 2015 Jul; 7(7): 71-76.

43. Da Silva EM, Glir DH, Gill AW, Giovanini AF, Furuse AY, Gonzaga CC. Efecto de la clorhexidina en la dentina con efectividad de enlaces en dos sistemas adhesivos después del almacenamiento en diferentes medios. J Dent. 2015 Nov-Dic; 26(6): 642-647.

44. Otamendi Saade C. Efecto de los compuestos eugenólicos en los materiales utilizados en endodoncia sobre la unión de los sistemas adhesivos. C Bóveda. 2003 Oct; 35: 9-2.

45. Mozayeni MA. Comparación de la actividad antifúngica del $2 \%$ de clorhexidina, hidróxido de calcio y nanoplata contra Candida Albicans. J Dent. 2015 Feb; 12 (2): 109-117.

46. Singh H, Kapoor P, Dhillon J, Kaur M. Evaluación de tres concentraciones diferentes de la clorhexidina por su sustantividad a la dentina humana. J Dent. 2014 Oct; 5(4):199-201.

47. Bolhari B, Dehghan S, Sharifiano MR, Bahador A, Pirmoazen S. Efecto de diferentes materiales de obturación en la actividad antimicrobiana residual del $2 \%$ de clorhexidina en la dentina en diferentes intervalos de tiempo: Un estudio in vivo. Ex. J Dent. 2015 Oct; 12(10):720-728.

48. Echeverri D, Alderete D. Efecto Antibacteriano in vitro de Clorhexidina al 2\% contra Enterococcus faecalis sobre dentina anteriormente irrigado con hipoclorito de sodio al 5\%. Int. J. Odontostomat. 2015 Feb. 9(1): 25-29.

49. Carrilho MR, Carvalho RM, Sousa ES. La sustantividad de la clorhexidina a la dentina humana. J dental. 2010 Ago; 26 (8): 779-85.

50. Shafiei F, Alikhani A, Alavi AA. Efecto de la clorhexidina en la unión de la durabilidad de los dos adhesivos de autograbado con y sin agente antibacteriano a la dentina. Dent Res J. 2013 Nov; 10(6): 795-801. 